UNIESSP II SIMPÓSIO NACIONAL

Desafios

\title{
Conhecimentos e práticas dos jovens universitários sobre IST: conduta sexual dos jovens graduandos
}

\author{
Davidson Miguel Silva \\ Mabelly Gonçalves Corrêa \\ Maria Regina Bernardo da Silva
}

\begin{abstract}
Como citar:
SILVA, Davidson Miguel; CORRÊA, Mabelly Gonçalves; SILVA, Maria Regina Bernardo da. Conhecimentos e práticas dos jovens universitários sobre IST: conduta sexual dos jovens graduandos. In: II SIMPÓSIO NACIONAL SOBRE ADOLESCÊNCIA: VULNERABILIDADE, PROTAGONISMOS E DESAFIOS, 2. 2016, São Paulo. Anais...[S.I]: 2016. p. 21-22.

DOI: http://dx.doi.org/10.22388/2525-5894.2016.003
\end{abstract}

Introdução: as Infecções Sexualmente Transmissíveis (IST) são importantes causas de procura aos serviços de saúde e podem provocar sérias complicações, como infertilidade, aborto espontâneo, malformações congênitas, infecções generalizadas e morte, se não tratadas. Também aumentam a chance de contaminação pelo HIV e muitas vezes são doenças de difícil deteç̧ão.

Objetivos: identificar o conhecimento dos universitários sobre a vulnerabilidade e o comportamento sexual dos mesmos em relação às Infecções Sexualmente Transmissíveis; Verificar o uso da camisinha como prevenção utilizada pelos universitários no ato sexual casual e/ou conjugal em relação à IST.

Métodos: foi realizado um estudo quantitativo, de natureza transversal, com base em dados obtidos de forma primária através de entrevistas estruturadas, individuais com graduandos dos cursos de administração e direito na instituição privada Universidade Castelo Branco, no Rio de Janeiro, com idades compreendidas entre 18 e 27 anos. Resultados: 48,64\% dos graduandos entrevistados não fizeram uso do preservativo na primeira relação sexual; $56,32 \%$ não se consideram vulneráveis a contrair alguma IST.

Conclusão: boa parte dos entrevistados apresenta déficit de informação sobre o porquê do uso da camisinha, tanto na relação conjugal quanto na relação extraconjugal e/ou casual. (Instituição de fomento: Universidade Castelo Branco).

Palavras-chaves: IST. Vulnerabilidade. Jovem. Enfermagem. Prevenção. 